\title{
Pheochromocytoma-induced shock: a case report
}

\author{
Stanley de Almeida Araújo ${ }^{a}$, Paula Alves Santos do Carmoª, Eduardo Paulino Júniora, \\ Isabela Nascimento Borges ${ }^{b}$, Luiz Otávio Savassi Rochac
}

Araújo SA, Carmo PAS, Paulino Júnior E, Borges IN, Rocha LOS. Pheochromocytoma-induced shock: a case report. Autopsy Case Rep [Internet]. 2012;2(3):21-30. http://dx.doi.org/10.4322/acr.2012.022

\section{ABSTRACT}

Because of its rarity, together with the variability and nonspecificity of its signs and symptoms, pheochromocytoma, a tumor arising from chromaffin cells, creates an unlucky paradox: it is often missed but only rarely found. Besides the association with arterial hypertension, often in the form of paroxysmal attacks, pheochromocytoma may also be associated, in up to $40 \%$ of cases, with orthostatic hypotension which, when present, provides a clue to the diagnosis of the tumor. Far more rare (about $2 \%$ of cases) is the clinical presentation in the form of shock, a possibility that, among other attributes, justifies the epithet "the great mimic" applied to the neoplasia. The authors report the case of a 51-year-old hypertensive woman whose death was erroneously attributed to septic shock. Autopsy disclosed an unsuspected left adrenal bulky pheochromocytoma with areas of hemorrhage and extensive central necrosis, pronounced pulmonary edema, left ventricular mural thrombus, and histological evidence of acute myocardial injury.

Keywords: Pheochromocytoma; Shock; Autopsy.

\section{CASE REPORT}

A 51-year-old female patient, who had systemic arterial hypertension and was under treatment with atenolol (50 mg/day), was admitted to the Federal University of Minas Gerais Hospital das Clínicas emergency room on January 9, 2012, at 3:19 a.m., having been referred from another emergency room. The patient presented a $4-5$ day history of increasingly intense clinical symptoms (as described in the transfer report and as reported by family members), including severe headache, neck pain, great anxiety, chest discomfort, nausea, vomiting, abdominal distension, tachypnea, dry cough, and lightheadedness. There was no mention of fever or urinary symptoms. Laboratory tests revealed significant leukocytosis $\left(22,500\right.$ leukocytes $\left./ \mathrm{mm}^{3}\right)$ with neutrophilia (segmented neutrophils, $79 \%$; band neutrophils, $5 \%$ ). On January 8,2012 , the patient received empirical treatment with ceftriaxone for suspected meningitis.

\footnotetext{
${ }^{a}$ Department of Pathology and Forensic Medicine - Faculdade de Medicina da Universidade Federal de Minas Gerais, 
Upon admission, the patient was alert (no disorientation) and was able to move all of her limbs. Her extremities were cold and poorly perfused. Her blood pressure (BP) was 110/70 $\mathrm{mmHg}$, heart rate was 140 beats per minute, respiratory rate was 42 breaths per minute, and peripheral oximetry was $85 \%$ on room air and $96 \%$ with supplemental oxygen at 5 $\mathrm{L} / \mathrm{min}$. Cardiac auscultation was normal, pulmonary auscultation revealed diffuse inspiratory rales in both hemithoraces, and the abdomen was distended. There was no neck stiffness or evident focal neurological deficits. The pupils were symmetric in size and light reflex was normal. Reflex examination showed a flexor plantar response, and deep tendon reflexes were normal. The remaining physical examination was unremarkable. A cranial computed tomography scan showed no significant changes, and a lumbar puncture was performed because of suspected meningitis. Working diagnoses also included endocarditis and severe sepsis secondary to pneumonia. Blood and urine cultures were requested, as were a chest X-ray and additional laboratory tests.

At 5 a.m. on January 9, 2012, the patient presented with severe hypoxemia and arterial hypotension $(B P=90 / 60 \mathrm{mmHg})$. Chest X-ray findings were consistent with acute respiratory distress syndrome. In addition to supplemental oxygen and intravenous saline, antibiotic therapy (clarithromycin and amoxicillin + clavulanate) was prescribed.

At approximately 5:45 a.m., the patient presented with psychomotor agitation and mental confusion, which were followed by respiratory arrest and, shortly thereafter, cardiac arrest (pulseless electrical activity), which reversed after 15 minutes of resuscitation procedures. The patient underwent orotracheal intubation and mechanical ventilation. Continuous sedation with fentanyl citrate and midazolam was prescribed. At 6:40 a.m., her blood pressure was undetectable, despite the administration of increasing doses of norepinephrine. With a fraction of inspired oxygen of $80 \%$ and a positive end-expiratory pressure of $7 \mathrm{cmH}_{2} \mathrm{O}$, her peripheral oxygen saturation remained at $98 \%$. Her abdomen remained distended, and her pupils were mydriatic.

At 8:30 a.m., the patient had another cardiac arrest (pulseless electrical activity, followed by asystole 10 minutes later). Resuscitation procedures were performed for 40 minutes - a cumulative dose of $15 \mathrm{mg}$ of epinephrine having been administered - but to no avail. The patient died at 9:10 a.m. After her husband and oldest daughter gave written informed consent, an autopsy was performed. After the death of the patient, we received the laboratory test results, which showed marked leukocytosis $(26,680$ leukocytes/ $\mathrm{mm}^{3}$; neutrophils, $82 \%$ ), slightly elevated troponin I levels $(0.9 \mathrm{ng} / \mathrm{mL})$, and markedly increased plasma D-dimer levels $(6,907.9 \mathrm{ng} / \mathrm{mL})$. The blood cultures (three samples) and the urine culture were negative. Cytology and biochemical analysis of cerebrospinal fluid were normal. Direct examination (including Gram staining and smear microscopy for acid-fast bacilli and Cryptococcus spp.) was negative, as were the cultures (including mycobacterial culture).

\section{AUTOPSY}

The autopsy revealed a massive left adrenal tumor measuring $8.0 \mathrm{~cm} \times 7.5 \mathrm{~cm} \times 5.0 \mathrm{~cm}$, accompanied by areas of hemorrhage and extensive central necrosis. The tumor, which weighed $112 \mathrm{~g}$, compressed the surrounding glandular parenchyma to the degree that only a narrow strip of peripheral cortex was visible (Figure 1).

The histological pattern was consistent with pheochromocytoma. The diagnosis was confirmed by immunohistochemistry by means of a strong positive reaction for chromogranin in tumor cells and for S-100 protein in sustentacular cells (Figure 2).

The heart weighed $270 \mathrm{~g}$. External examination revealed left atrial enlargement, a slightly enlarged right ventricular outflow tract and a rounded tip, which was attributed to left ventricular enlargement. Examination of the cardiac chambers revealed a recent left ventricular mural thrombus (Figure 3).

There were no valve lesions, nor obstruction of epicardial or intramural coronary arteries. The histological examination revealed, particularly in the left ventricular myocardium, acute cardiomyocyte injury, characterized by loss of striation, increased cytoplasmic eosinophilia, and contraction band necrosis (Figure 4A). The abovementioned lesions were frequently found in association with inflammatory infiltrate, predominantly composed of neutrophils (Figure 4B). Immunohistochemical analysis of left ventricular myocardium samples revealed generally weak and irregular positivity for C4d antigen in cardiomyocytes with contraction band necrosis (Figures 4C and 4D). Histologically intact cardiomyocytes and endothelial cells tested negative for C4d. 

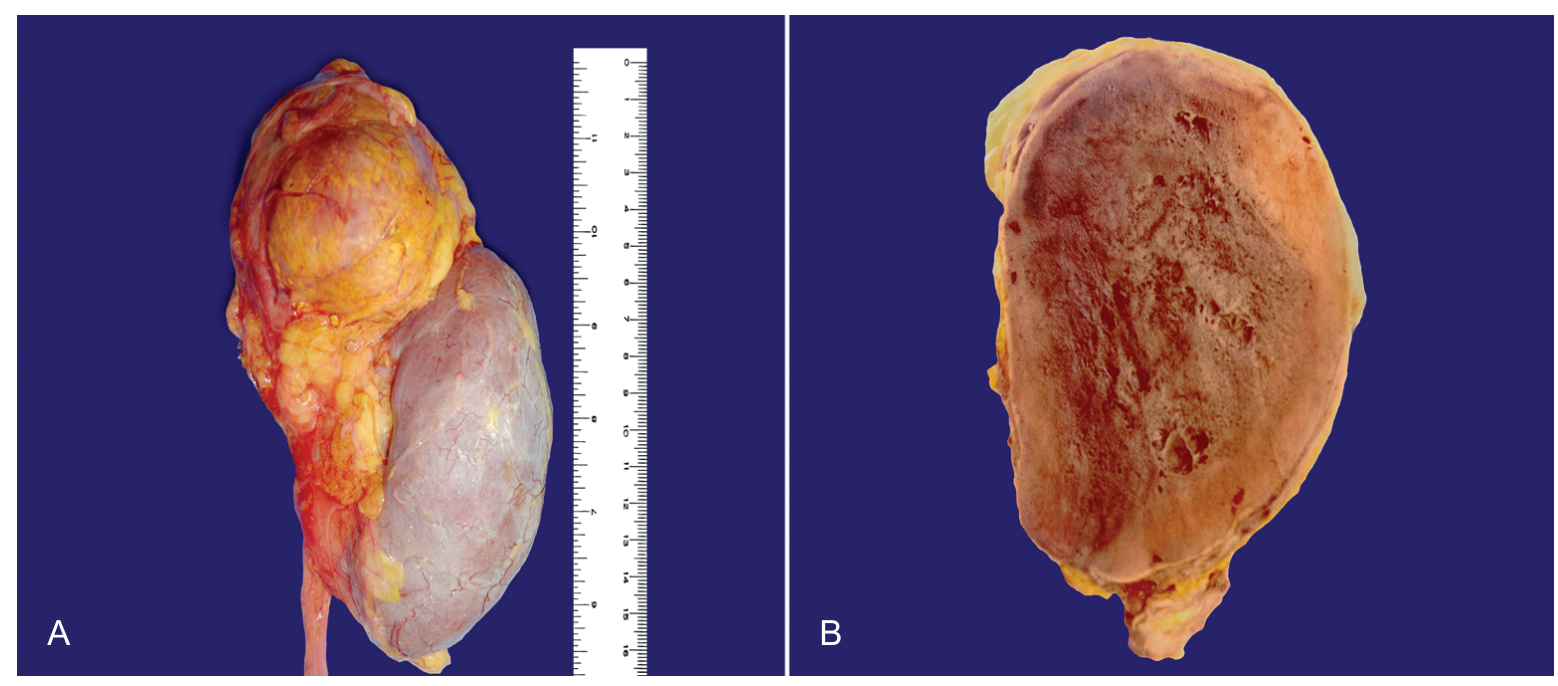

Figure 1 - Gross examination. A - Large tumor mass in the topography of the left adrenal gland; B - Cutoff surface of the tumor with areas of hemorrhage, extensive central necrosis, and compression of the surrounding glandular parenchyma, only a narrow strip of peripheral cortex remaining visible.
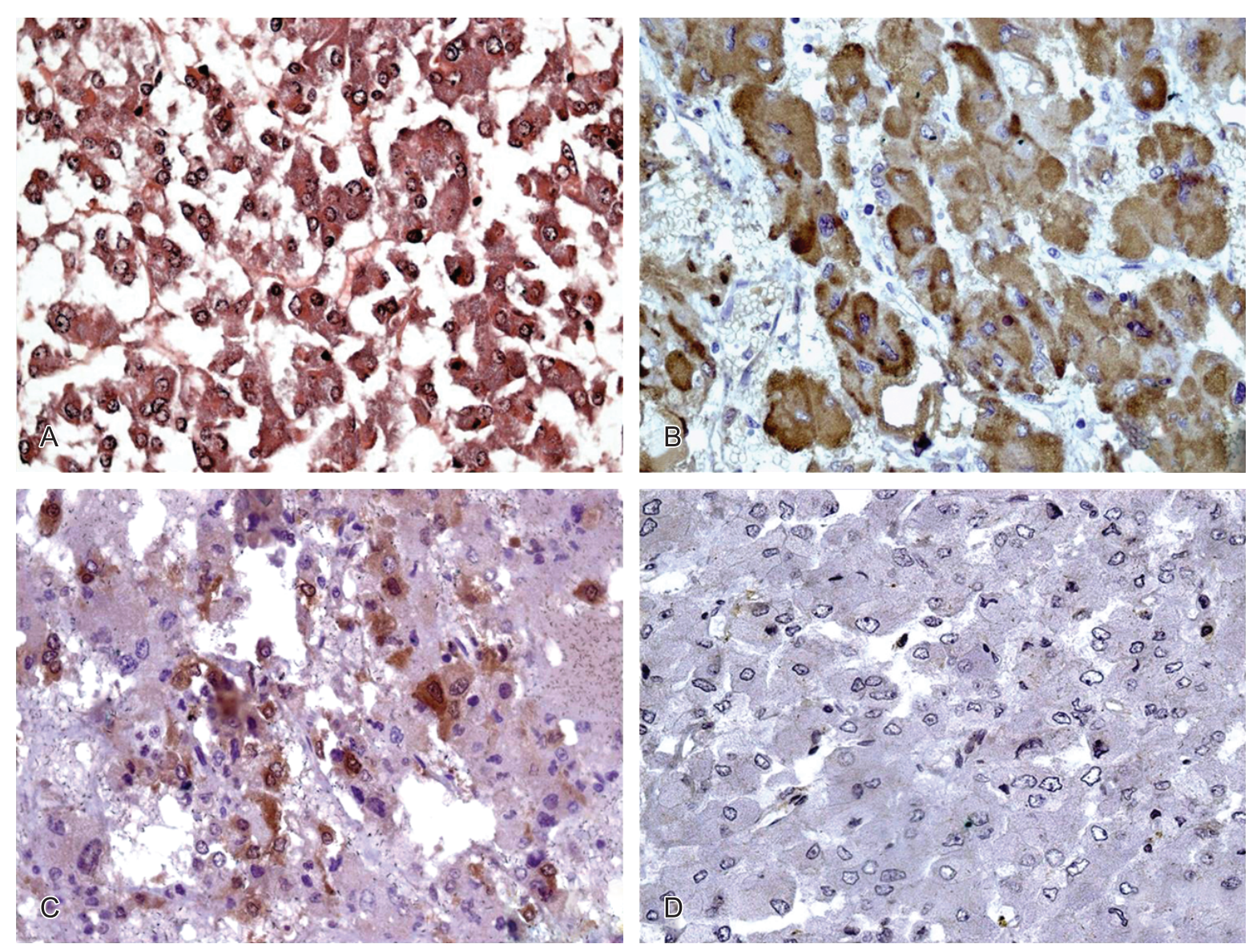

Figure 2 - Photomicrographs. A - Histological appearance of the tumor (hematoxylin and eosin [H\&E]); B - Immunohistochemistry: strong positivity for chromogranin antigen in neoplastic cells; C - Immunohistochemistry: positivity for S-100 protein antigen in sustentacular cells; D - Immunohistochemistry: negativity for epithelial membrane antigen in tumor cells.

The lungs showed congestion, marked acute alveolar edema, areas of recent alveolar hemorrhage, and mild (predominantly neutrophilic) inflammatory exudate in multiple systematized foci, amid sparse fibrin deposition and desquamation of pneumocytes (Figures 5A and 5B). There was also recent thrombosis of a small-sized pulmonary artery branch (Figure 5C) and thickening of the walls of small arteries and arterioles due to hypertrophy of the tunica muscularis, accompanied by mild intimal hyperplasia in some areas (Figure 5D). 

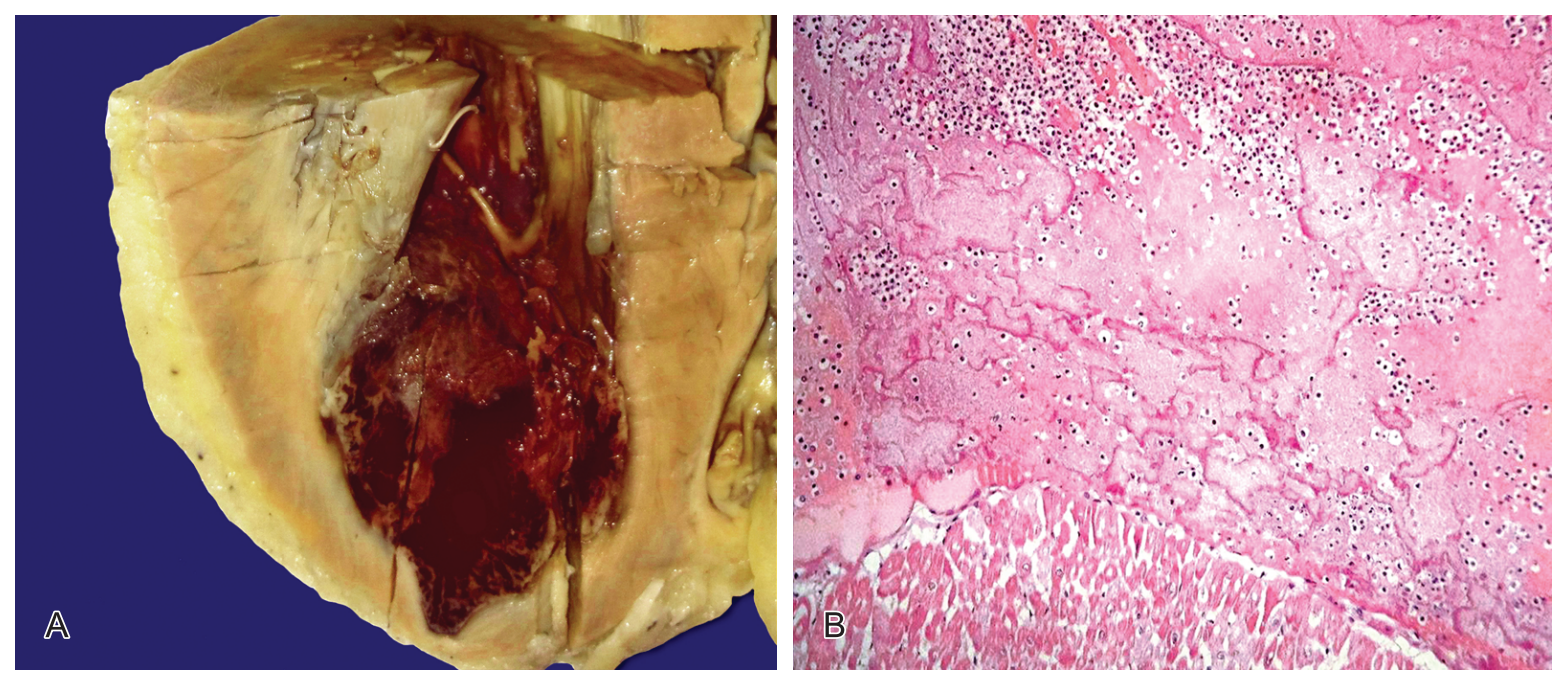

Figure 3 - A - A recent left ventricular mural thrombus: a view of the tip (anterior aspect); B - Photomicrograph (H\&E): histological appearance of the left ventricular mural thrombus.

Other pathological findings included acute tubular necrosis, mild acute hepatic passive congestion (along with hepatocellular degeneration), splenic congestion, multiple systematized foci of cortical hypoxic-ischemic injury in the brain, multinodular colloid goiter, and intramural uterine leyomiomas.

\section{DISCUSSION}

Pheochromocytoma (derived from the Greek word phaios, dark) is a tumor arising from chromaffin cells, so named for their affinity for chromium. Indeed, tumor fragments incubated in a solution of potassium dichromate become brown or dark brown as a result of the oxidation of stored catecholamines. Pheochromocytoma is a capricious disease; when extensively searched, it is rarely found, as it accounts for less than $0.3 \%$ of cases of hypertension; on the other hand, when present, it is often missed (as in the present case). Moreover, due to its unpredictable behavior as well as the catastrophic clinical course presented by many patients, pheochromocytoma has been likened to a dormant volcano that can suddenly erupt.

Traditionally, the mention of pheochromocytomas evokes the "rule of $10 \mathrm{~s}$ ":

- $10 \%$ of all pheochromocytomas are extraadrenal (derived from branchiomeric, intravagal, or aortic sympathetic paraganglia)
- $10 \%$ are bilateral (except for those that constitute certain familial syndromes, in which this proportion can be as high as $50 \%$ )

- $10 \%$ are malignant (the presence of metastases being the only reliable criterion for malignancy)

- $10 \%$ are not accompanied by arterial hypertension (possibly due to the fact that they secrete substances such as dopamine)

It was previously believed that $10 \%$ of all pheochromocytomas were associated with germline mutations (genes RET, NF1, VHL; and, in the case of paragangliomas, the genes SDHD, SDHC, and SDHB), therefore constituting familial syndromes (multiple endocrine neoplasia types $2 \mathrm{~A}$ and $2 \mathrm{~B}$, neurofibromatosis type 1, von Hippel-Lindau disease, and familial pheochromocytoma-paraganglioma syndromes types 1, 3, and 4). Recently, the last item of the "rule of 10s" was reformulated, because it appears that $25 \%$ rather than $10 \%$ of all pheochromocytomas are associated with germline mutations. ${ }^{1}$

Adrenal pheochromocytomas arise from the medulla of the gland, which can be understood as a sympathetic ganglion whose neurons have lost their axons. Arterial hypertension is present in $90 \%$ of all cases of adrenal pheochromocytomas and consistently manifests in one third of such cases, not differing much, in its presentation, from that of essential hypertension. In the remaining two thirds, there are paroxysmal attacks characterized by a significant increase in blood pressure, accompanied by headache, profuse sweating, palpitations, tremors, vasomotor changes (pallor followed by flushing), 

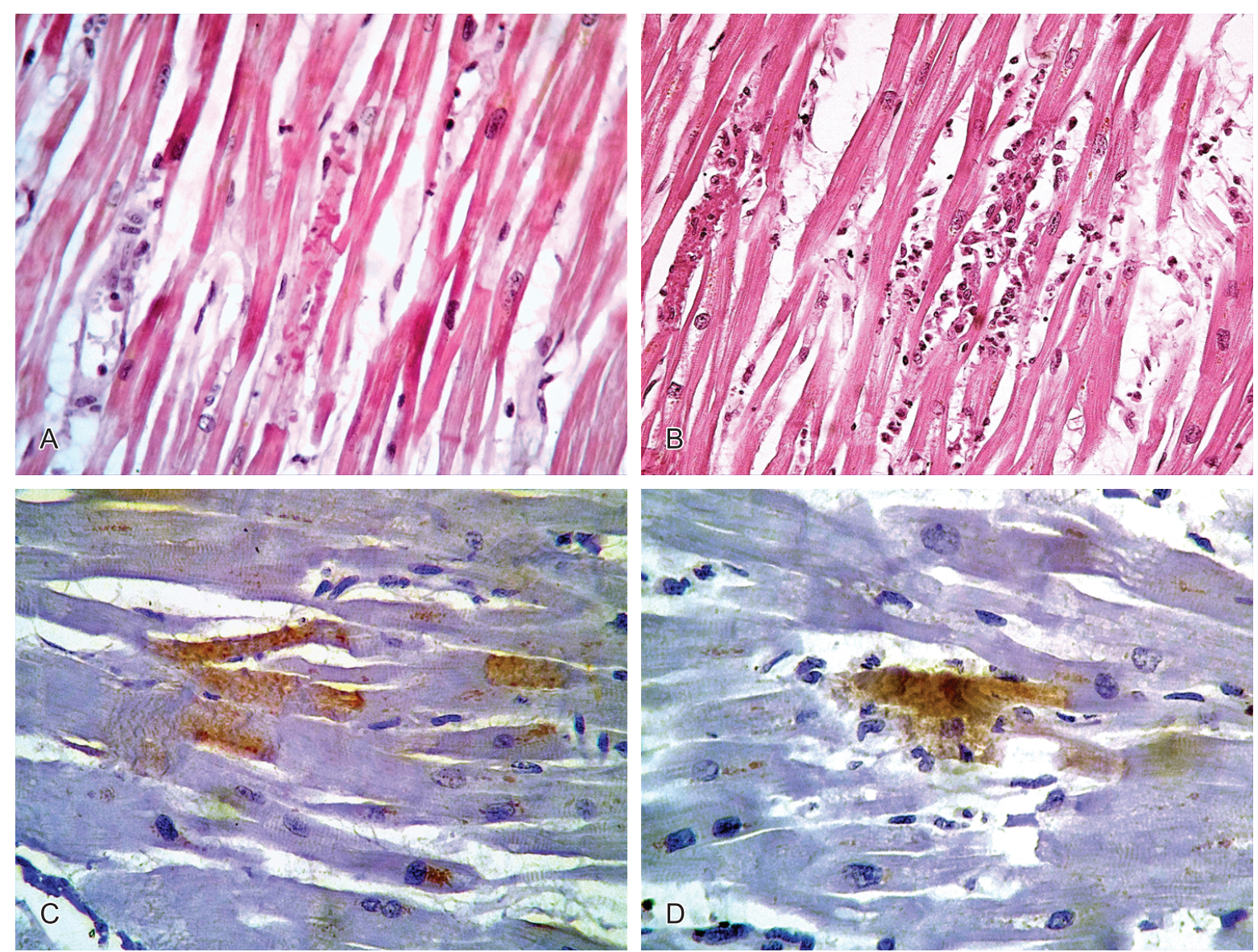

Figure 4 - Photomicrographs. A - Cardiomyocytes with loss of striation, increased cytoplasmic eosinophilia, and contraction band necrosis (H\&E); B - Inflammatory infiltrate in an area of cardiomyocyte necrosis (H\&E); C - Immunohistochemical staining for C4d: necrotic cardiomyocytes testing positive for the antigen; D - A necrotic cardiomyocyte surrounded by inflammatory cells and testing positive for $\mathrm{C} 4 \mathrm{~d}$.

intense anxiety, and a sense of impending death. The differential diagnosis with other conditions, such as panic attacks, is therefore required. In the period between paroxysmal attacks, blood pressure can be normal. More often than not, however, paroxysmal attacks of hypertension overlap with chronically elevated blood pressure. Such attacks can occur spontaneously or be precipitated by sudden movements, physical exercise, emotional stress, abdominal palpation, vaginal delivery, trauma, drugs (such as decongestants, ionic intravenous contrast agents, and selective serotonin reuptake inhibitors), or surgical removal of the tumor. Such attacks constitute true hypertensive emergencies, given that target organs can be severely affected, with the development of cardiac arrhythmias, acute pulmonary edema, myocardial ischemia, or hypertensive encephalopathy, the last of the four eventually giving rise to posterior reversible encephalopathy syndrome (PRES); the pathogenesis of the syndrome is controversial, the white matter in the parietal-occipital regions being most commonly affected. ${ }^{2,3}$ In practice, true hypertensive emergencies, which require immediate blood pressure reduction, should be distinguished from "hypertensive pseudoemergencies", which are not accompanied by target organ involvement and are often treated inappropriately in emergency rooms. ${ }^{4-6}$

In addition to being associated with arterial hypertension, pheochromocytoma is associated, in up to $40 \%$ of cases, with orthostatic hypotension, to the extent that the presence of such a manifestation provides a clue to the diagnosis of the tumor. Pheochromocytoma presenting clinically as shock is far rarer (and disconcerting); such a clinical presentation, together with other attributes, justifies the epithet "the great mimic", which is applied to the neoplasia. ${ }^{7-11}$ A review of 539 pheochromocytoma cases, published in 1989, identified 11 cases (2\%) in which the tumor initially presented as shock. ${ }^{12}$ Fourteen years later, when the 69th Annual Meeting of the American College of Chest Physicians was held, a literature review was published, and 47 cases of pheochromocytoma presenting clinically as shock have been identified in the 1966-2003 period..$^{13}$ The mean age of the patients was 44 years, and $68 \%$ were female. Only $23 \%$ had previously documented 


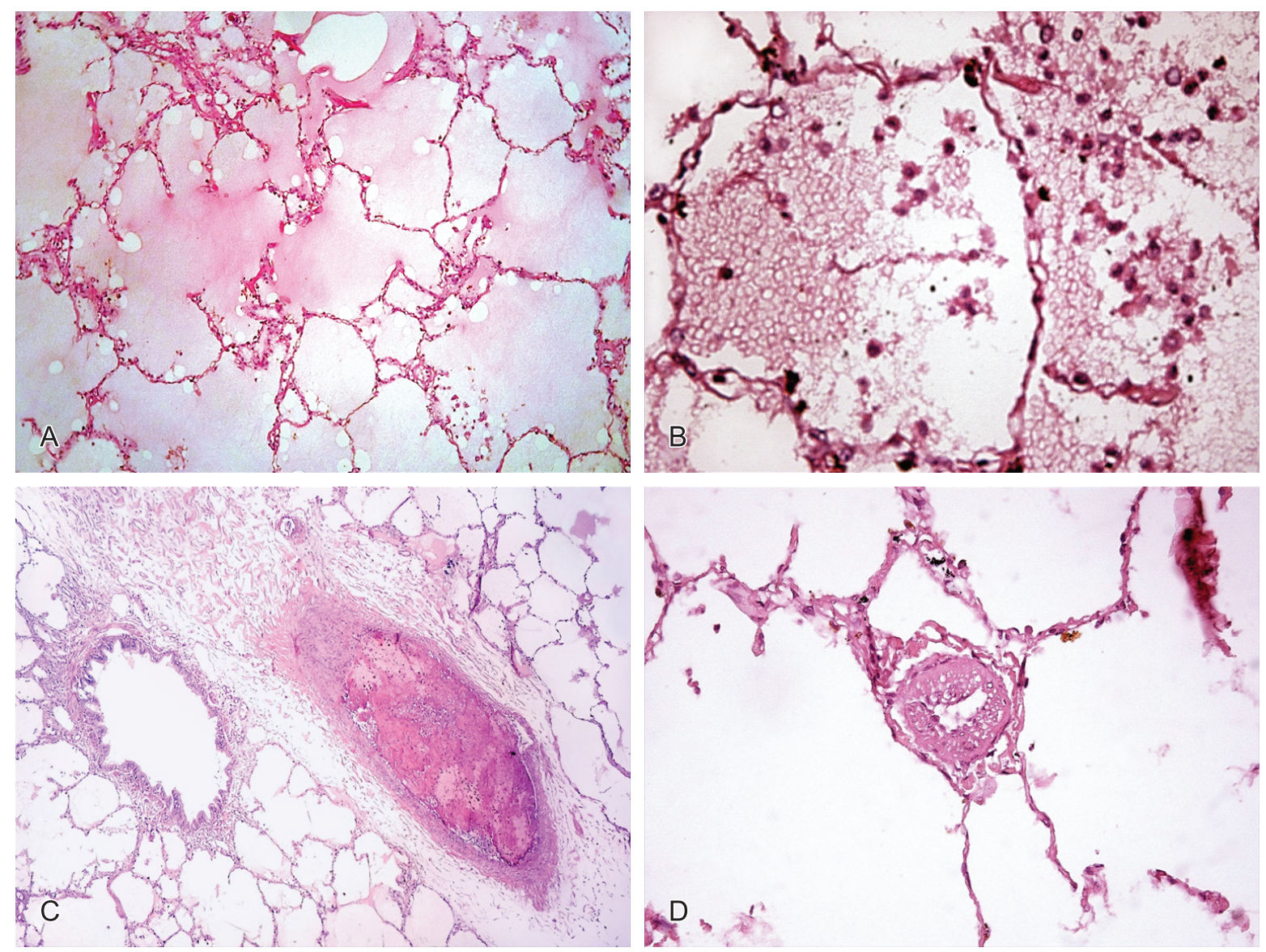

Figure 5 - Photomicrographs: histological features of the lungs (H\&E). A - Alveolar edema; B - Recent alveolar hemorrhage and mild inflammatory exudate; C - Thrombosis of a small-sized pulmonary artery branch; D - Thickening of the wall of a pulmonary arteriole due to hypertrophy of the tunica muscularis.

arterial hypertension. Shock was preceded by mild abdominal trauma in 2 cases. In addition, drugs such as metoclopramide, phenothiazines, imipramine, beta-blockers, amiodarone, and marijuana had been used by $30 \%$ of the patients prior to the onset of shock. In $23 \%$ of the cases, the diagnosis was confirmed only at autopsy. The mean tumor diameter was $7.0 \mathrm{~cm}$, central tumor necrosis, bleeding within the tumor, or both having been reported in $78 \%$ of the cases. The authors of the review emphasized that it is imperative to screen critically ill patients for pheochromocytoma when such patients present with a large tumor mass in the topography of the adrenal gland, with central necrosis, bleeding, or both. The authors also stated that an emergency adrenalectomy should be performed after clinical stabilization in case the diagnosis is confirmed. They also emphasized that although arterial hypotension is believed to be associated with tumors that secrete predominantly adrenaline, only 6 of the 20 patients in whom catecholamine levels were determined were found to have adrenaline-secreting tumors.
In the present case report, the autopsy finding of a large $(8.0 \mathrm{~cm} \times 7.5 \mathrm{~cm} \times 5.0 \mathrm{~cm})$, clinically unsuspected tumor with hemorrhage and extensive central necrosis is of note and is consistent with the literature, as is the fact that the tumor was misdiagnosed as septic shock (antibiotics being therefore prescribed). The previous use of a betablocker (atenolol, $50 \mathrm{mg} /$ day) for the treatment of arterial hypertension is also of note. As a cardioselective beta-blocker, primarily blocking beta1 receptors, atenolol would not be as deleterious as propranolol in a similar context. However, atenolol can lose its cardioselectivity if higher doses are prescribed. By blocking beta-2 receptors (which cause vasodilation), noncardioselective beta-blockers should be avoided in patients with pheochromocytoma, unless alpha-adrenergic receptors are previously blocked by the use of drugs such as phenoxybenzamine (a nonselective alpha-adrenergic receptor blocker) or prazosin hydrochloride (an alpha-1-adrenergic receptor blocker).

The pathogenesis of the shock caused by pheochromocytoma is too complex and has yet to be 
fully understood. Two closely related mechanisms have been proposed: hypovolemia (absolute or relative) and myocardial injury (direct or indirect) accompanied by decreased cardiac output. ${ }^{14}$

Absolute hypovolemia is assumed to result from increased capillary permeability leading to third-space shifting, decreased blood pressure, hemoconcentration, and, occasionally, noncardiogenic pulmonary edema in the presence of normal pulmonary capillary wedge pressure. ${ }^{15}$ Relative hypovolemia is attributed to various factors, including peripheral beta-adrenergic adrenaline and dopamine effect, prostaglandin activity and attenuation of the vasoconstrictor response due to downregulation of alpha-1-adrenergic receptors, particularly deleterious in case of massive tumor necrosis accompanied by an abrupt decrease in catecholamine concentrations. In the case reported here, we cannot rule out the role of increased capillary permeability in triggering pulmonary edema (as revealed by autopsy), based on the radiological findings (which were suggestive of acute respiratory distress syndrome) as well as on the neutrophil recruitment (as revealed by microscopic examination), the latter being a histological finding reported in the early stages of diffuse alveolar damage.

Indirect myocardial injury is attributed to microvascular dysfunction mediated by adrenergic hyperactivity, whereas direct myocardial injury is ascribed to the toxic effect of catecholamines on the heart muscle. This effect is marked by the generation of free radicals with increased calcium influx across the sarcolemma and, first and foremost, by cyclic adenosine monophosphate-mediated intracellular calcium overload, resulting in adenosine triphosphate depletion, enzyme activation (phospholipases, proteases, and endonucleases) and, ultimately, cardiomyocyte necrosis and apoptosis. ${ }^{16,17}$

The hypothesis that sympathoadrenal system hyperactivity can cause acute myocardial injury and even death was raised 70 years ago by Walter Cannon, in a provocative essay entitled "'Voodoo' Death". ${ }^{18}$ Although his observations, at a distance, examines anecdotal case reports from African countries, Australia, New Zealand, Haiti, and Brazil, the noted physiologist attributes the fatal outcome to the catecholamine storm triggered by the terror and sense of annihilation experienced by credulous natives overwhelmed by the feeling of being held hostage to supernatural powers. Seventy years ago, Walter Cannon had no way to evaluate the role of factors other than sympathoadrenal hyperactivity - such as the role of hypothalamic corticotropin-releasing hormone released after signals from the amygdala reach the hypothalamus - in triggering "voodoo death". ${ }^{19}$ However, his thoughts on such an intriguing issue resonate today, the role of adrenergic hyperactivity in the etiopathogenesis of acute left ventricular dysfunction having been demonstrated in the following clinical conditions ${ }^{20}$ :

- Transient left ventricular apical ballooning syndrome, also known as takotsubo cardiomyopathy and, more popularly, "broken-heart syndrome", ${ }^{21}$ a severe but potentially reversible condition that primarily affects women in the 50-80 year age bracket, usually after acute physical stress, acute emotional stress, or both (e.g., the beating of a 76-year-old woman by her own daughter in Portugal ${ }^{22}$ and elderly women going through an earthquake in Japan ${ }^{23}$ ), and is characterized by sudden-onset dyspnea, chest pain, conspicuous electrocardiographic changes that can mimic acute myocardial infarction, absence of obstructive coronary disease (as determined by coronary cineangiography), and apical akinesis or hypokinesis associated with hyperkinesis of the basal left ventricular segments

- Acute left ventricular dysfunction associated with acute subarachnoid hemorrhage, most commonly characterized by hypokinesis of the basal left ventricular segments and apical hyperkinesis (a pattern known as "inverted takotsubo") and, more rarely, by the takotsubo pattern ${ }^{24-27}$

- Acute left ventricular dysfunction in critically ill patients, such as those with severe sepsis

- Acute left ventricular dysfunction associated with exogenous catecholamine administration ${ }^{28}$

- Acute left ventricular dysfunction associated with pheochromocytoma, particularly in cases that are accompanied by shock

The common denominator of the abovementioned conditions is probably the deleterious effect of catecholamines on the myocardium. In the case of pheochromocytoma, as occurs in cases of subarachnoid hemorrhage, the left ventricle may assume either the takotsubo cardiomyopathy pattern or the inverted takotsubo cardiomyopathy one, as if both were sides of the same coin. ${ }^{29-34}$ It is assumed that this is due to differences among individuals regarding the anatomy of the cardiac sympathetic innervation or the distribution of adrenergic receptors in different myocardial segments. ${ }^{21}$

In the present case report, left ventricular performance was not evaluated by Doppler echocardiography, because of the incorrect diagnosis of septic shock and, first and foremost, the short 
emergency room stay (less than 6 hours). Moreover, serum troponin I levels (single determination) were found to be only slightly elevated. Nevertheless, the conspicuous histopathological changes constituted evidence of heart muscle damage, which was probably due to adrenergic hyperactivity and shock. In addition, it is possible that heart muscle damage was also due to the administration of high doses of norepinephrine, in a vain attempt to control hemodynamic instability. The histopathological changes included positivity for C4d antigen in necrotic cardiomyocytes, C4d being an inactive split product of C3 convertase.

The deposition of C4d antigen indicates recent complement activation through the classical pathway. In heart transplant recipients, endomyocardial biopsy samples testing positive for C4d constitute a criterion for the diagnosis of antibody-mediated allograft rejection, correlating well with the detection of anti-donor serum alloantibodies. Moreover, it is known that complement is involved in exacerbation of myocarditis and mediates cardiomyocyte injury in acute myocardial infarction and reperfusion injury. In the case of acute myocardial infarction, C4d is an early indicator of cardiomyocyte necrosis before the influx of inflammatory cells. ${ }^{35}$ In addition, a recent study reported that immunohistochemical staining was strongly positive for $\mathrm{C} 4 \mathrm{~d}$ antigen along the microvasculature and in cardiomyocytes with contraction band necrosis in a fatal case of takotsubo cardiomyopathy, in which myocardial injury appears to be due to excessive circulating catecholamines (as occurs in cases of pheochromocytoma). ${ }^{36}$ Finally, it should be noted that, according to some authors, cases in which supposedly necrotic cardiomyocytes test negative for C4d should be interpreted as cases of artifactual contraction band injury. ${ }^{37}$

The importance of myocardial injury in the etiopathogenesis of shock due to pheochromocytoma can be confirmed in practice by the need for different cardiorespiratory support measures (use of an intraaortic balloon pump, use of a DeBakey ventricular assist device, and extracorporeal membrane oxygenation) in order to stabilize patients and therefore allow emergency adrenalectomy. ${ }^{38-41}$

Intracardiac thrombosis has been reported, although rarely, in cases of pheochromocytoma, being usually accompanied by abnormal left ventricular segmental contraction. ${ }^{42-45}$ In the present case report, the mural thrombus, which occupied a significant portion of the left ventricle cavity, possibly impaired left ventricular filling, therefore playing a role in the hemodynamic instability of the patient and in the pathogenesis of pulmonary edema. In addition, comparing the clinical data with the autopsy findings, it is reasonable to assume that the left ventricular mural thrombus and the thrombosis of a small-sized pulmonary artery branch have a relationship with the markedly increased plasma D-dimer levels $(6,907.9$ $\mathrm{ng} / \mathrm{mL}$ ) found in a blood sample collected shortly before the death of the patient.

\section{ACKNOWLEDGMENTS}

We would like to thank Professor Leonardo Maurício Diniz and Professor Moisés Salgado Pedrosa for their valuable collaboration.

\section{REFERENCES}

1. Elder EE, Elder G, Larsson C. Pheochromocytoma and functional paraganglioma syndrome: no longer the $10 \%$ tumor. J Surg Oncol. 2005;89:193-201. http://dx.doi.org/10.1002/ jso. 20177

2. Moorthy S, Subramaniam TS, Prabhu NK, Sree KK, Nair RG. Posterior reversible encephalopathy syndrome in a child with pheochromocytoma. Indian J Radiol Imaging. 2002;12:321-4.

3. Majic T, Aiyagari V. Cerebrovascular manifestations of pheochromocytoma and the implications of a missed diagnosis. Neurocrit Care. 2008;9:378-81. http://dx.doi. org/10.1007/s12028-008-9105-8

4. Nobre F, Chauchar F, Viana JM, Pereira GJV, Lima NKC. Avaliação do atendimento do hipertenso em serviço de urgência e em ambulatório de hipertensão. Arq Bras Cardiol. 2002; 78:156-8. Portuguese. http://dx.doi.org/10.1590/ S0066-782X2002000200003

5. Sobrinho S, Correia LCL, Cruz C, et al. Ocorrência e preditores clínicos de pseudocrise hipertensiva no atendimento de emergência. Arq Bras Cardiol. 2007;88:579-84. Portuguese. http://dx.doi.org/10.1590/S0066-782X2007000500013

6. Monteiro Junior FC, Anunciação FAC, Salgado Filho $\mathrm{N}$, et al. Prevalência de verdadeiras crises hipertensivas e adequação da conduta médica em pacientes atendidos em um pronto-socorro geral com pressão arterial elevada. Arq Bras Cardiol. 2008;90:269-73. Portuguese. http://dx.doi. org/10.1590/S0066-782X2008000400006

7. Fred HL, Allred DP, Garber HE, Retiene K, Lipscomb H. Pheochromocytoma masquerading as overwhelming infection. Am Heart J. 1967;73:149-54. http://dx.doi.org/10.1016/00028703(67)90141-X

8. Hocqueloux L, Barboteu M, Vincent F, Meria P, Le Gall JR. Phéochromocytome simulant un choc septique. Arch Mal Coeur Vaiss. 1997;90:1313-6. French. 
9. Ford J, Rosenberg F, Chan N. Pheochromocytoma manifesting with shock presents a clinical paradox: a case report. Can Med Assoc J. 1997;157:923-5. PMid:1228218.

10. Shapira MY, Zuckerman E, Zuebi T, Jurim O. Pheochromocytoma multi-organ crisis: nonseptic hyperthermia and shock. Harefuah. 1998;135:104-6. PMid:9885652.

11. Mohamed HA, Aldakar MO, Habib N. Cardiogenic shock due to acute hemorrhagic necrosis of a pheochromocytoma: a case report and review of the literature. Can J Cardiol. 2003;19:5736. PMid:12717495.

12. Bergland BE. Pheochromocytoma presenting as shock. Am J Emerg Med. 1989;7:44-8. http://dx.doi.org/10.1016/07356757(89)90084-3

13. Schifferdecker B, Atef A, Spodick DH, Aragam J. Pheochromocytoma characteristics in adrenergic shock. Chest. 2003;124:177S.

14. Schifferdecker B, Kodali D, Hausner E, Aragam J. Adrenergic shock - An overlooked clinical entity? Cardiol Rev. 2005;13:69-72. PMid:15705255.

15. Leeuw PW, Waltman FL, Birkenhäger WH. Noncardiogenic pulmonary edema as the sole manifestation of pheochromocytoma. Hypertension. 1986;8:810-2. PMid:3744472.

16. Wittstein IS, Thiemann DR, Lima JAC, et al. Neurohumoral features of myocardial stunning due to sudden emotional stress. N Engl J Med. 2005;352:539-48. PMid:15703419.

17. Mann DL. Basic mechanisms of disease progression in the failing heart: The role of excessive adrenergic drive. Prog Cardiovasc Dis. 1998; 41(Suppl. 1):1-8. http://dx.doi. org/10.1016/S0033-0620(98)80025-X

18. Cannon WB. "Voodoo" death. Am Anthropol. 1942; 44:16981. PMid:1447285.

19. Sternberg EM. Walter B. Cannon and " 'voodoo' death": A perspective from 60 years on. Am J Public Health. 2002; 92:1564-6.

20. Richard C. Stress-related cardiomyopathies. Ann Intensive Care. 2011 [cited 2012 Aug 21];1:39. Available from: http:// www.ncbi.nlm.nih.gov/pmc/articles/PMC3224539/pdf/21105820-1-39.pdf. http://dx.doi.org/10.1186/2110-5820-1-39

21. Akashi YJ, Goldstein DS, Barbaro G, Ueyama T. Takotsubo cardiomyopathy. A new form of acute, reversible heart failure. Circulation. 2008;118:2754-62. http://dx.doi.org/10.1161/ CIRCULATIONAHA.108.767012

22. Assunção LA, Grams AC, Ribeiro CS, Magalhães T. "Broken-heart" syndrome in an elder abuse case: forensic considerations from the case. Forensic Sci Med Pathol. 2011;7:217-21. http://dx.doi.org/10.1007/s12024010-9212-7
23. Sato M, Fujita S, Saito A, et al. Increased incidence of transient left ventricular apical ballooning (so-called 'Takotsubo' cardiomyopathy) after the mid-Niigata Prefecture earthquake. Circ J. 2006;70:947-53. PMid:16864923.

24. Ennezat PV, Pesenti-Rossi D, Aubert JM, et al. Transient left ventricular basal dysfunction without coronary stenosis in acute cerebral disorders: A novel heart syndrome (inverted Takotsubo). Echocardiography. 2005;22:599-602.

25. Lee VH, Connolly HM, Fulgham JR, Manno EM, Brown Junior $\mathrm{RD}$, Wijdicks EF. Tako-tsubo cardiomyopathy in aneurysmal subarachnoid hemorrhage: an underappreciated ventricular dysfunction. J Neurosurg. 2006;105:264-70. PMid:16060897.

26. Tommaso I, Ossana R, Polosa D, Mecca D. Takotsubo cardiomyopathy after subarachnoid hemorrhage: A case report. Internet J Neurosurg. 2008 [cited 2012 Aug 21]; 5. Available from: http://www.ispub.com/journal/the-internetjournal-of-neurosurgery/volume-5-number-1/takotsubocardiomyopathy-after-subarachnoid-hemorrhage-a-casereport.html. http://dx.doi.org/10.5580/147d

27. Franco C, Khaled B, Afonso L, Raufi M. Acute subarachnoid hemorrhage and cardiac abnormalities: Takotsubo cardiomyopathy or neurogenic stunned myocardium? A case report. Cases J. 2010 [cited 2012 Jul 12];3:81. Available from: http://www.casesjournal.com/content/3/1/81

28. Abraham J, Mudd JO, Kapur N, Klein K, Champion HC, Wittstein IS. Stress cardiomyopathy after intravenous administration of cathecolamines and beta-receptor agonists. J Am Coll Cardiol. 2009;53:1320-5. http://dx.doi.org/10.1016/j. jacc.2009.02.020

29. Sanchez-Recalde A, Costero O, Oliver JM, Iborra C, Ruiz E, Sobrino JA. Pheochromocytoma-related cardiomyopathy. Inverted takotsubo contractile pattern. Circulation. 2006;113:e738-9. http://dx.doi.org/10.1161/ CIRCULATIONAHA.105.581108

30. Takizawa M, Kobayakawa N, Uozumi H, et al. A case of transient left ventricular ballooning with pheochromocytoma, supporting pathogenetic role of cathecolamines in stressinduced cardiomyopathy or takotsubo cardiomyopathy. Int J Cardiol. 2007;114:e15-e17. http://dx.doi.org/10.1016/j. ijcard.2006.07.125

31. Zegdi R, Parisot C, Sleilaty G, Deloche I, Fabiani JN. Pheochromocytoma-induced inverted Takotsubo cardiomyopathy: a case of patient resuscitation with extracorporeal life support. J Thorac Cardiovasc Surg. 2008;135:434-5. http://dx.doi.org/10.1016/j. jtcvs.2007.08.068

32. Di Valentino M, Balestra GM, Christ M, Raineri I, Oertli D, Zellweger MJ. Inverted Takotsubo cardiomyopathy due to pheochromocytoma. Eur Heart J. 2008;29:830. PMid:17954493.

33. Zielén P, Klisiewicz A, Januszewicz A, et al. Pheochromocytoma-related 'classic' takotsubo 
cardiomyopathy. J Hum Hypertens. 2010;24:363-6. http:// dx.doi.org/10.1038/jhh.2009.115

34. Ueda H, Hosokawa Y, Tsujii U, et al. An autopsy case of left ventricular apical ballooning probably caused by pheochromocytoma with persistent ST-segment elevation. Int J Cardiol. 2011;149:e50-e52.

35. Jenkins CP, Cardona DM, Bowers JN, Oliai BR, Allan RW, Normann SJ. The utility of C4d, C9, and troponin T immunohistochemistry in acute myocardial infarction. Arch Pathol Lab Med. 2010;134:256-63. http://dx.doi.org/10.1016/j. ijcard.2009.03.096

36. Hudacko RM, Fyfe BS, Mehra A, Moreyra AE. Takotsubo cardiomyopathy: pathologic insights from a fatal case. Internet J Cardiol. 2010 [cited 2012 Aug 2];8(1). Available from: http://www.ispub.com/journal/the-internet-journal-ofcardiology/volume-8-number-1/takotsubo-cardiomyopathypathologic-insights-from-a-fatal-case.html

37. Hudacko R, Varghese S, Fyfe B. Pattern and evolution of C4d staining of ischemic myocardial injury: Implications for the interpretation of post-transplant endomyocardial biopsies. N A J Med Sci 2012;5:64-70.

38. Grinda JM, Bricourt MO, Salvi S, et al. Unusual cardiogenic shock due to pheochromocytoma: Recovery after bridge-tobridge (extracorporeal life support and DeBakey ventricular assist device) and right surrenalectomy. J Thorac Cardiovasc Surg. 2006;131:913-4. PMid:16580454.

39. Grasselli G, Foti G, Patroniti N, Rona R, Perlangeri MV, Pesenti A. Extracorporeal cardiopulmonary support for cardiogenic shock caused by pheochromocytoma: A case report and literature review. Anesthesiology. 2008;108:95962. Pmid:18431133.

40. Wu XM, Chen JJ, Wu CK, Lin LY, Tseng CD. Pheochromocytoma presenting as acute myocarditis with cardiogenic shock in two cases. Inter Med. 2008;47:2151-5. PMid:19075541.

41. Salinas CL, Gómez Beltran OD, Sánchez-Hidalgo JM, Bru RC, Padillo FJ, Rufián S. Emergency adrenalectomy due to acute heart failure secondary to complicated pheochromocytoma: a case report. World J Surg Oncol. 2011,9:49. http://dx.doi. org/10.1186/1477-7819-9-49

42. Heindel SW, Maslow AD, Steriti J, Mashikian JS. A patient with intracardiac masses and an undiagnosed pheochromocytoma. J Cardiothorac Vasc Anesth. 2002;16:338-43. http://dx.doi. org/10.1053/jcan.2002.124144

43. Mrdovic I, Perunicic J, Asanin M, Matic M, Vasiljevic Z, Ostojic M. Transient left ventricular apical ballooning complicated by a mural thrombus and outflow tract obstruction in a patient with pheochromocytoma. Tex Heart Inst J. 2008;35:480-2. PMid:19156249.

44. Zhou W, Ding SF. Concurrent pheochromocytoma, ventricular tachycardia, left ventricular thrombus, and systemic embolization. Inter Med. 2009;48:1015-9. PMid:19525590.

45. Hou R, Leathersich AM, Ruud BT. Pheochromocytoma presenting with arterial and intracardiac thrombus in a 47-yearold woman: a case report. J Med Case Rep. 2011;5:310. http://dx.doi.org/10.1186/1752-1947-5-310

\section{Conflict of interest: None}

Submitted on: $12^{\text {th }}$ July 2012

Accept on: $1^{\text {st }}$ August 2012

Correspondence: Luiz Otávio Savassi Rocha

Rua João Evangelista, 233, apto. 301 - Bairro São Pedro - Belo Horizonte/MG - Brazil

CEP: 30330-140 - Phone: +55 (31) 3221-2089

E-mail: savassi@estaminas.com.br 